\title{
Endoscopic hemostasis using an over-the-scope clip for massive bleeding after percutaneous endoscopic gastrostomy removal: a case report
}

\author{
Sun Young Moon ${ }^{1,2}$, Min Kyu Jung ${ }^{1,2}$, Jun Heo ${ }^{1,2}$ \\ ${ }^{1}$ Department of Internal Medicine, Kyungpook National University School of Medicine, Daegu; ${ }^{2}$ Department of Internal Medicine, Kyungpook National University \\ Hospital, Daegu, Korea
}

Percutaneous endoscopic gastrostomy (PEG) is a common method for providing long-term enteral nutrition to patients. PEG tube placement and removal are relatively safe; generally, a PEG tube can be removed using gentle traction, and excessive bleeding is rare. The over-the-scope clip system is a new device that can be used for gastrointestinal hemostasis and for closing gastrointestinal fistulae. In the present case, a 68-year-old male patient had to remove the PEG tube because of persistent leakage around the PEG tube. Although it was gently removed using traction, incessant bleeding continued, with a Rockall score of 5 points, even after hemocoagulation was attempted. An over-the-scope clip device was used to achieve hemostasis and fistula closure.

Keywords: Bleeding; Gastrocutaneous fistula; Over-the-scope clip; Percutaneous endoscopic gastrostomy

\section{INTRODUCTION}

Percutaneous endoscopic gastrostomy (PEG) is a widely used method for providing long-term enteral nutrition to patients who require tube-feeding support due to impaired oral intake. ${ }^{1,2}$ The use of PEG has gradually risen with the increase in life expectancy; PEG tube placement and removal is a common and relatively safe procedure. ${ }^{3}$

PEG tubes need to be removed when the infection persists, when there is cracking or clogging, and when buried bumper syndrome occurs. PEG tubes with rigid bumpers are usually re-

Received: November 13, 2020 Revised: January 13, 2021

Accepted: January 15, 2021

Correspondence: Min Kyu Jung

Department of Internal Medicine, Kyungpook National University Hospital, 130 Dongdeok-ro, Jung-gu, Daegu 41944, Korea.

E-mail: minky1973@knu.ac.kr

(c) This is an Open Access article distributed under the terms of the Creative Commons Attribution Non-Commercial License (http://creativecommons.org/licenses/by-nc/4.0/) which permits unrestricted non-commercial use, distribution, and reproduction in any medium, provided the original work is properly cited. moved using an endoscopic method wherein the tube is cut and withdrawn with an endoscopic snare. PEG tubes with flexible bumpers are usually removed using a traction method where the tube is pulled out through the skin. If the PEG tube type is unknown, the endoscopic method is recommended due to direct visualization. ${ }^{4}$ Generally, a PEG tube can be easily removed using gentle traction. It is uncommon to witness excessive bleeding after removing a PEG catheter. ${ }^{5}$ The over-the-scope clip (OTSC) system is a new full-thickness suturing device that can be used for gastrointestinal hemostasis as well as for closing gastrointestinal fistulae. ${ }^{6,7}$ This system is relatively safe, easy to use, effective, and has a high success rate in hemostasis and defect closure. ${ }^{6,8}$

We report a case of excessive bleeding just after removing the PEG tube. We stop bleeding and close the fistula also using an OTSC device.

\section{CASE REPORT}

A 68-year-old male patient with hilar cholangiocarcinoma and 
metastatic pulmonary cancer underwent adjuvant chemotherapy. He had recurrent aspiration pneumonia and complained of severe dysphagia with an Eastern Cooperative Oncology Group performance status of 3. He underwent PEG tube insertion using a PEG-24-PULL-S (Cook Medical LLC, Bloomington, IN, USA), without any complications. However, leakage around the PEG site subsequently persisted for 90 days. Endoscopic findings showed a well-positioned PEG tube without signs of gastric ulcer. The PEG tube was gently removed by traction; however, blood flowed continuously and uncontrollably from the insertion site. Endoscopy revealed blood gushing from the PEG tract. When electrocoagulation using an electrocoagula- tion probe (3 minutes; MTW Endoskopie, Wesel, Germany) failed to stop the bleeding, we attempted hemostasis with an OTSC device. A 12/6 t-type OTSC (Ovesco Endoscopy AG, Tübingen, Germany) was successfully used to simultaneously achieve hemostasis and close the gastrocutaneous fistula. Endoscopy revealed no active bleeding and a closed fistula (Fig. 1). The total procedural time was 13 minutes. The changes in vital signs from before to after endoscopy were as follows: blood pressure from $145 / 86$ to $121 / 80 \mathrm{mmHg}$, pulse rate from 105 to 97 beats per minute, and respiratory rate from 22 to 20 breaths per minute, while $\mathrm{SaO}_{2}$ was at $99 \%$. Laboratory tests showed no thrombocytopenia, and his Rockall score was 5. Laboratory
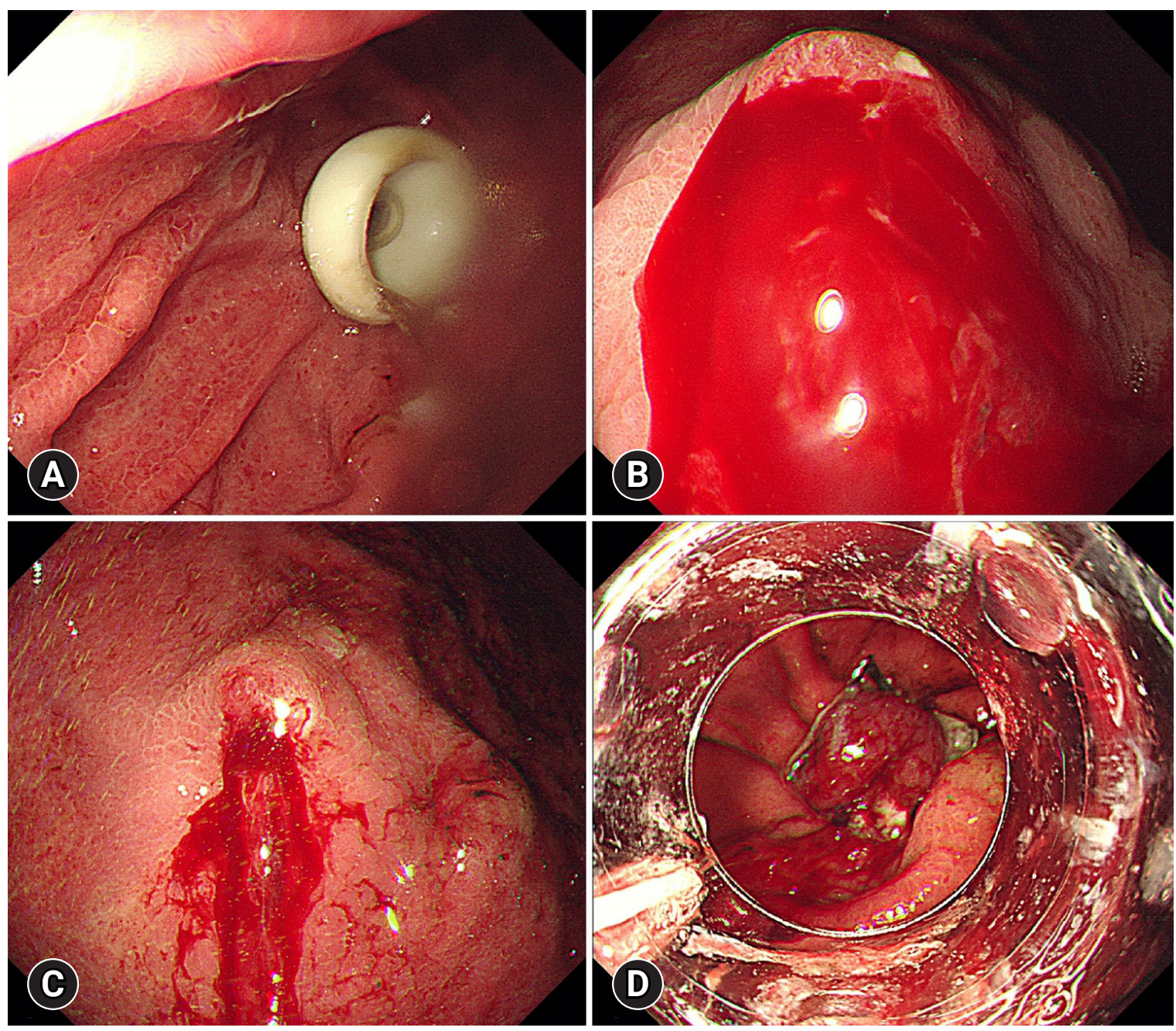

Fig. 1. Endoscopic findings. (A) A well-positioned percutaneous endoscopic gastrostomy (PEG) tube before removal. (B) Blood jetting from the PEG tract after removing the PEG tube. (C) Persistence of active bleeding despite endoscopic hemocoagulation therapy. (D) The tissue at the gastric orifice was captured with the over-the-scope clip device. The gastrocutaneous fistula was closed, and endoscopic hemostasis was also successfully achieved. 
findings before and after the endoscopy showed the following changes: hemoglobin count from $10.9 \mathrm{~g} / \mathrm{dL}$ to $10.5 \mathrm{~g} / \mathrm{dL}$, platelet count from $230 \times 10^{3} / \mu \mathrm{L}$ to $194 \times 10^{3} / \mu \mathrm{L}$, prothrombin time from 14.7 seconds to 14.4 seconds, and activated prothrombin time from 27.3 seconds to 28.0 seconds. He had no risk factors for bleeding tendency, such as the administration of antithrombotic or antiplatelet agents. Following the procedure, leakage from the fistula and bleeding ceased and the patient started a diet on the next day; the last follow-up was 8 weeks after the procedure.

\section{DISCUSSION}

The OTSC system is a full-thickness suturing device that can be used through flexible endoscope working channels. OTSC devices have a higher clinical success rate for gastrointestinal hemostasis compared with standard endoscopic hemostasis in patients who either use anticoagulants or those with an endoscopic Rockall score of 6 or higher. ${ }^{9}$ Given its strength, it is also effective for gastrointestinal mucosal defects and perforation. Therefore, the OTSC system also achieved a high success rate in endoscopic closure of gastrocutaneous fistula after PEG tube removal in immunocompromised patients and those with multiple comorbidities. ${ }^{6,8}$ It also showed a lower incidence rate of rebleeding and rebleeding-associated mortality. ${ }^{10}$ This new endoscopic device has various indications. It is used not only for hemostasis in gastrointestinal bleeding but also for closing gastrointestinal fistulae or anastomotic leakage. ${ }^{11-13}$

In this case study, the incessant bleeding was thought to be due to the damage to the gastric mucosa that was in contact with the PEG tube when it was removed using the traction method. Because bleeding persisted after attempting endoscopic hemostasis with a Rockall score of 5 points, we used an OTSC device that could simultaneously achieve hemostasis with direct tamponade and closure of the gastrocutaneous fistula.

Ponsky-type PEGs can be removed easily by the traction method. There are few complications after the removal, and massive bleeding rarely occurs. ${ }^{5}$ However, PEG insertion is commonly performed in patients with deteriorating and/or various comorbid conditions. Bleeding can be fatal when it cannot be controlled through endoscopic hemostasis. In patients with general weakness or immunodeficiencies, spontaneous closure of the fistula after PEG removal may not occur. Many studies have reported high closure success rates with an OTSC device similar to the one used in this case. ${ }^{6,8,12}$

In conclusion, as described in this case report, when inces- sant bleeding continues after the removal of PEG, even after attempting hemocoagulation, an OTSC device can be used as an alternative to achieve both hemostasis and fistula closure.

\section{Conflicts of Interest}

The authors have no potential conflicts of interest.

\section{Funding}

None.

\section{Author Contributions}

Conceptualization: MKJ, JH; Data curation: SYM; Methodology: MKJ, JH; Writing-original draft: SYM; Writing-review \& editing: MKJ, SYM, JH.

\section{ORCID}

Sun Young Moon

Min Kyu Jung

Jun Heo

https://orcid.org/0000-0001-6610-5129 https://orcid.org/0000-0001-8749-408X https://orcid.org/0000-0003-3180-1655

\section{REFERENCES}

1. Deitch EA, Winterton J, Li M, et al. The gut as a portal of entry for bacteremia. Role of protein malnutrition. Ann Surg 1987;205:681692.

2. Gauderer MW, Ponsky JL, Izant RJ. Gastrostomy without laparotomy: a percutaneous endoscopic technique. J Pediatr Surg 1980; 15:872-875

3. Sheehan JJ, Hill AD, Fanning NP, et al. Percutaneous endoscopic gastrostomy: 5 years of clinical experience on 238 patients. Ir Med J 2003;96:265-267.

4. Prosser B. Common issues in PEG tubes: what every fellow should know. Gastrointest Endosc 2006;64:970-972.

5. Kim JK, Kim YK, Lee YR, et al. A case of massive bleeding after peg removal by traction method. Korean J Gastrointest Endosc 1999;19(Suppl 2):33S-37S.

6. Heinrich H, Gubler C, Valli PV. Over-the-scope-clip closure of long lasting gastrocutaneous fistula after percutaneous endoscopic gastrostomy tube removal in immunocompromised patients: a single center case series. World J Gastrointest Endosc 2017;9:85-90.

7. Dişibeyaz S, Köksal A, Parlak E, et al. Endoscopic closure of gastrointestinal defects with an over-the-scope clip device: a case series and review of the literature. Clin Res Hepatol Gastroenterol 2012;36:614- 


\section{C clinical endoscopy}

621.

8. Singhal S, Changela K, Culliford A, et al. Endoscopic closure of persistent gastrocutaneous fistulae, after percutaneous endoscopic gastrostomy (PEG) tube placement, using the over-the-scope-clip system. Therap Adv Gastroenterol 2015;8:182-188.

9. Wedi E, Fischer A, Hochberger J, et al. Multicenter evaluation of first-line endoscopic treatment with the OTSC in acute non-variceal upper gastrointestinal bleeding and comparison with the Rockall cohort: the FLETRock study. Surg Endosc 2018;32:307-314.

10. Schmidt A, Gölder S, Goetz M, et al. Over-the-scope clips are more effective than standard endoscopic therapy for patients with recurrent bleeding of peptic ulcers. Gastroenterology 2018;155:674-686. e676.

11. Sulz MC, Bertolini R, Frei R, et al. Multipurpose use of the overthe-scope-clip system ("Bear claw") in the gastrointestinal tract: Swiss experience in a tertiary center. World J Gastroenterol 2014;20: 16287-16292.

12. Kobara H, Mori H, Nishiyama N, et al. Over-the-scope clip system: a review of 1517 cases over 9 years. J Gastroenterol Hepatol 2019;34:22-30.

13. Kirschniak A, Subotova N, Zieker D, et al. The over-the-scope clip (OTSC) for the treatment of gastrointestinal bleeding, perforations, and fistulas. Surg Endosc 2011;25:2901-2905. 